\title{
Assessing the Adsorptive and Photodegradative Efficiencies of ZSM-11 Synthesized from Rice Husk Ash
}

\author{
Michael Akrofi Anang $D^{D},{ }^{1}$ Ruphino Zugle, ${ }^{2}$ and Baah Sefa-Ntiri ${ }^{3}$ \\ ${ }^{1}$ University of Cape Coast, College of Agriculture and Natural Sciences, School of Physical Sciences, Department of Chemistry, \\ Industrial Chemistry Unit, Cape Coast, Ghana \\ ${ }^{2}$ University of Cape Coast, College of Agriculture and Natural Sciences, School of Physical Sciences, Department of Chemistry, \\ Cape Coast, Ghana \\ ${ }^{3}$ University of Cape Coast, College of Agriculture and Natural Sciences, School of Physical Sciences, Department of Physics, \\ Cape Coast, Ghana
}

Correspondence should be addressed to Michael Akrofi Anang; makrofi@ucc.edu.gh

Received 22 May 2020; Revised 16 July 2020; Accepted 18 August 2020; Published 9 September 2020

Academic Editor: Claudio Cameselle

Copyright ( 2020 Michael Akrofi Anang et al. This is an open access article distributed under the Creative Commons Attribution License, which permits unrestricted use, distribution, and reproduction in any medium, provided the original work is properly cited.

\begin{abstract}
Rice husk was used to synthesize zeolite (ZSM-11). FTIR and X-ray diffraction methods were used to characterize the product. The synthesized zeolite was used to treat underground water from some communities in Cape Coast considering parameters such as total dissolved solids, total hardness, conductivity, nitrate, and phosphate. The percentage reduction in $\mathrm{PO}_{4}^{3-}$ was $96.1 \%$ in Ebubonko and $92.5 \%$ in Apewosika. Similarly, the $\mathrm{NO}^{3-}$ levels also decreased significantly in Kwaprow. The adsorption capability was also determined by using it to remove $\mathrm{Pb}^{2+}$ and $\mathrm{Zn}^{2+}$ from laboratory prepared solutions with varying masses. The percentage reduction recorded $90.57 \%$ and $86.61 \%$ for the $1.0 \mathrm{~g}$ whilst the $1.5 \mathrm{~g}$ showed $93.26 \%$ and $89.36 \%$, respectively. It was also realized that the adsorption process followed a pseudo-first-order rather than the pseudo-second-order process with their $R^{2}$ values of 0.9929 and 0.8503 for the pseudo-first-order and 0.9662 and 0.6912 for the second-order for $\mathrm{Pb}^{2+}$ and $\mathrm{Zn}^{2+}$, respectively. The adsorption capacity also favored the Freundlich isotherm with $R^{2}$ values of 0.7578 and 0.642 rather than Langmuir isotherm with $R^{2}$ values of 0.1742 and 0.3856 for $\mathrm{Pb}^{2+}$ and $\mathrm{Zn}^{2+}$, respectively. The photodegradation ability of the synthesized zeolite was analyzed using rhodamine blue (RhB) and methyl orange $(\mathrm{MO})$. The process was realized to favor the pseudo-second-order with $R^{2}$ values of 0.9986 and 0.0007 and a constant $K_{2}$ of 0.035 and 0.021 for RhB and MO, respectively, whereas the pseudo-first-order showed an $R^{2}$ value of 0.9376 and 0.9757 with $K_{1}$ values of 0.03 and 0.02 .
\end{abstract}

\section{Introduction}

Zeolites are crystalline aluminosilicate group materials that have pores and frames in molecular dimensions (less than $2 \mathrm{~nm}$ ), composed of tetrahedral units $\mathrm{SiO}_{4}{ }^{4-}$ and $\mathrm{AlO}_{4}{ }^{4-}$ interconnected with each other [1]. They are also described as crystalline microporous aluminosilicates built up of a 3dimensional framework of $\left[\mathrm{SO}_{4}\right]^{4-}$ and $\left[\mathrm{AlO}_{4}\right]^{5-}$ tetrahedral linked by strong oxygen atoms [2]. They are a group of hydrated aluminosilicates of alkali or alkali Earth metals: principally sodium, potassium, magnesium, barium, lithium, and calcium $[3,4]$ containing pores and channels of molecular dimensions that are used widely in industry as ion-exchange resins, [5], adsorbents [6], and catalysts. ZSM11 is a shape-selective catalyst that has unique channel structures with 10-membered ring openings and rather unusual catalytic properties $[7,8]$ having a similar structure of ZSM-5 [8] and therefore having important values in the petrochemical industry.

ZSM-11 is a MEL type zeolite that has high silica content and has similarities with zeolite type MFI (ZSM-5) [9]. Tetrabutylammonium hydroxide $(\mathrm{TBAOH})$ is an organic template commonly used for the synthesis of ZSM-11 but the silica source is relatively expensive and environmentally unfriendly [10]. Heavy metals are generally considered to be those whose density exceeds $5 \mathrm{~g} \mathrm{~cm}^{-1}$ [11]. Presently, the 
heavy metals contamination in drinking water is being investigated by many scientists in both the natural and anthropogenic sources [12-14]. They are known to be very toxic and can accumulate in the living organism and are nonbiodegradable as well. Lead and zinc are two important heavy metals that are well-known toxics, used in metallurgy, tannery manufacturing, pulp and paper industries, metal products, paints and varnishes, battery manufacturing industries, galvanizing plants, and so forth. [15]. Zinc can travel through the food chain via bioaccumulation and becomes harmful and can cause anemia, pancreatic damage, protein metabolism disturbance, arteriosclerosis, and respiratory disorders. Synthetic dyes are mostly used by textile, food, plastic, paper, printing, pharmaceutical, and cosmetic industries. They are water-soluble and as such become a common organic pollutant in industrial wastewater. Large volumes of these cationic dyes are consumed by the textile industries and most of them usually discharge their effluents into drains. These effluents end up in water bodies which cause devastating effects on the environment and human well-being. There is, therefore, the need to research into dyes removal from wastewaters [16]. The conventional methods for treating wastewater include chemical precipitation, coagulation-flocculation, floatation, filtration, ion-exchange, reverse osmosis, membrane filtration, evaporation recovery, and electrochemical technologies [17, 18]. These conventional techniques have their inherent limitations such as less efficiency, sensitive operating conditions, and production of secondary sludge and further the disposal is a costly affair [19] and although these processes are commonly used, they do not eliminate the waste, involve high operating costs, and can generate toxic secondary pollution [20]. Adsorption is universally accepted and the most widely used method of water treatment as it involves the least sophisticated instrumentation with easy operations and can be operated with a wide range of adsorbents [21] as it involves simple design, low-cost adsorbents, and treatment cost, and mild conditions are criteria for selection of best mode and adsorbent [22]. Photodegradation is an emerging branch of advanced oxidation technologies used for water and wastewater treatment that has been widely documented for its ability to degrade indiscriminately almost all water pollutants such as dyes [20] and have been proven to be of interest due to its efficiency in degrading recalcitrant organic compounds [23]. It consists of processes such as thermic plasma [24], Fenton radiation [25], photocatalysis, sonolysis, and ozonization [26] and combinations of these are increasingly adopted in the destruction of organic contaminants, due to their high efficiency, simplicity, good reproducibility, and easy handling [27]. Synthetic zeolites obtained from industrial, municipal, or agricultural waste materials especially rice husk ash (RHA) and coal fly ash (CFA) have huge potential as a cost-effective environmentally friendly solution that can improve the efficiency of wastewater treatment [28]. Polyaniline/CoFeC ${ }_{6} \mathrm{~N}_{6}$ nanocomposite has been used for the sorption of $\mathrm{Ni}$ (II) and $\mathrm{Pb}$ (II) as investigated by Moazeai et al., 2018 [29]. Cu (II), Cd (II), and $\mathrm{Pb}$ (II) present in industrial effluents have been removed using Moringa stenopetala seed husk by Temesgen et al., 2018 [30]. In this research work, Zeolite (ZSM-11) was synthesized from RHA and was used for the treatment of groundwater samples from some communities within the Cape Coast metropolis in Ghana. It was also used for the removal of zinc $(\mathrm{Zn})$ and lead $(\mathrm{Pb})$ from a laboratory prepared solution. The synthesized ZSM-11 was also used to explore the degradation characteristics of rhodamine blue and methyl orange. Figure 1 shows the chemical structures of the dyes used in this research work.

\section{Materials and Methods}

2.1. Preparation of Rice Husk into Rice Husk Ash. The pretreatment process of the rice husk can be considered in stages involving mechanical, thermal, and chemical. Dry raw rice husk $(\mathrm{RH})$ was sieved to eliminate residual rice and clay particles [31]. It was washed with water to remove dirt, rinsed with distilled water, and dried in an oven at a temperature of $100^{\circ} \mathrm{C}$ overnight. The metallic impurities were removed with hydrochloric acid [32]. Rice husk was acid leached with $3 \mathrm{M} \mathrm{HCl}$ for 24 hours, acidified, washed with distilled water, and oven-dried at $100^{\circ} \mathrm{C}$. It was then calcined in a furnace (Nabertherm model) at $750^{\circ} \mathrm{C}$ for 6 hours to eliminate incorporated organic matter to obtain the rice husk ash (RHA).

2.2. Synthesis of Zeolite from Rice Husk Ash. The RHA was mixed with aqueous $\mathrm{NaOH}$, heated at $100^{\circ} \mathrm{C}$ for 1 hour, and filtered to produce sodium silicate $\left(\mathrm{Na}_{2} \mathrm{SiO}_{3}\right)$ solution. Bauxite was pretreated and an appropriate amount was weighed and digested in $4 \mathrm{M} \mathrm{NaOH}$ solution and heated at $150^{\circ} \mathrm{C}$ for 4 hours in an electrical oven to obtain sodium aluminate solution. A calculated portion of the sodium aluminate was mixed and stirred vigorously for 1 hour. The resulting gel was homogenized and transferred into a Teflon autoclave and crystallized at $110^{\circ} \mathrm{C}$ for 24 hours without stirring or agitation for the crystals to precipitate, be filtered, and be dried.

2.3. Zero Point Charge of Synthesized Zeolite. The $\mathrm{pH}$ at which the sorbent surface charge takes a zero value is defined as point of zero charge ( $\mathrm{pHpzc}$ ) where the charge of the positive surface sites is equal to that of the negative ones. This information allows the researchers to evaluate the ionization of functional groups and their interaction with metal species in solution. If the $\mathrm{pH}$ of the solution is higher than pHpzc, the sorbent surface is negatively charged and could interact with the metal positive species and when the $\mathrm{pH}$ is lower than pHpzc, the solid surface is positively charged and could interact with negative species. The point of zero charge of the synthesized zeolite was determined using the potentiometric mass titration process as applied by Bourikas et al., 2003 [33].

2.4. Groundwater Sampling. Groundwater samples were taken from six communities within the Cape Coast $\mathrm{Me}$ tropolis, in the central region of Ghana, namely, Abura, 
<smiles>CCN(CC)c1ccc2c(-c3ccccc3C(=O)O)c3ccc(=[N+](CC)CC)cc-3oc2c1</smiles>

(a)

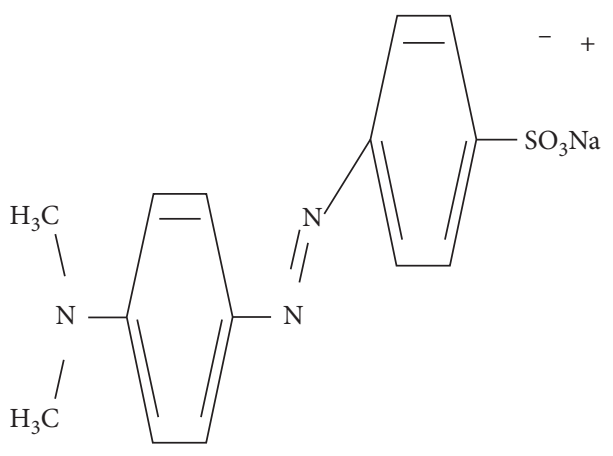

(b)

FIgURE 1: The chemical structures of rhodamine blue and methyl orange.

Kwaprow, Apewosika, Ammamoma, Ebubonko, and Amoyaw. Physicochemical parameters of the samples such as turbidity, total dissolved solids, total hardness, conductivity, nitrate, phosphate, chloride, and sulfate were determined.

2.4.1. Sample Preparation. Groundwater samples were taken from the bottom of the wells, which had average depths between $15 \mathrm{~m}$ and $20 \mathrm{~m}$ into $500 \mathrm{ml}$ bottles which have been washed and rinsed with deionized water. It was kept in a cool box with a temperature below $4^{\circ} \mathrm{C}$ before transporting to the laboratory for analysis. On-site analyses of temperature, electrical conductivity, total dissolved solids (TDS), and $\mathrm{pH}$ were conducted using portable $\mathrm{HACH}$ conductivity meter and Metrolin model 691-pH meter; alkalinity was also determined on-site using HACH Digital Multisampler Titrator Model 1690. The concentrations of major ions nitrate $\mathrm{NO}^{3-}$ and phosphate $\mathrm{PO}_{4}^{3-}$ were determined spectrophotometrically in the laboratory using portable HACH DR/890.

\subsubsection{Laboratory Analysis}

(1) Sample Treatment. $1 \mathrm{~g}$ mass of the synthesized zeolite was added to $100 \mathrm{ml}$ of the groundwater samples and stirred for two (2) hours using the magnetic stirrer. The physicochemical parameters were measured after the treatment period and recorded. Laboratory prepared concentrations of lead $\left(\mathrm{Pb}^{2+}\right)$ and zinc $\left(\mathrm{Zn}^{2+}\right)$ solutions were prepared and a mass of the zeolite was added. It was also placed on a magnetic stirrer and, under batch conditions with consistent time intervals of $30 \mathrm{~min}, 10 \mathrm{ml}$ was taken and centrifuged. The final concentration of the metal solution was determined using the Atomic Absorption Spectrophotometer (AAS).

(2) Photodegradation of Rhodamine Blue and Methyl Orange. Methyl orange and rhodamine blue were chosen as representative dye contaminants to help evaluate the photodegradation activity of ZSM-11 with absorption band at $464 \mathrm{~nm}$ and $530 \mathrm{~nm}$ under sunlight. $1 \mathrm{~g}$ of the synthesized ZSM-11 was dissolved in $100 \mathrm{ml}$ of the dye solution and stirred for almost $30 \mathrm{~min}$ in the dark to enable the establishment of an adsorption-desorption equilibrium between
ZSM-11 and the MO or RhB. It was, then, placed under sunlight and after some $30 \mathrm{~min}$ intervals, the samples were taken on a batch basis and centrifuged to separate the zeolite before analyzing with the UV-Vis 1600 Spectrophotometer The efficiency of the degradation process was calculated using the formulae [34]

$$
\% \eta=\left(\frac{C_{o}-C_{f}}{C_{o}}\right) * 100,
$$

where $\% \eta=$ degradation efficiency, $C_{o}=$ initial dye concentration, and $C_{f}=$ final dye concentration.

2.5. Determination of Percentage Removal/Reduction. The percentage reduction of the concentrations of the groundwater sample was calculated using the formulae

$$
R \%=\frac{\left(C_{O}-C_{t}\right)}{C_{O}} \times 100,
$$

where $R \%=$ percentage removal/reduction of parameters/ metal ion from solution, $C_{o}=$ initial concentration $(\mathrm{mg} / \mathrm{L})$ of metal ions/in solutions, and $C_{t}=$ final concentration $(\mathrm{mg} / \mathrm{L})$ of metal ion in solution.

\subsection{Kinetic Studies}

2.6.1. Sorption Kinetics. The sorption kinetics of the process was determined using the equations which were used by Anang et al. [35] in their research work on Chrysophyllum albidum. The pseudo-first-order kinetic model equation is given as

$$
\left.\frac{\mathrm{d} q_{t}}{\mathrm{~d} t}=k_{1} \mathrm{C} q_{e}-q_{t}\right)
$$

After this equation has been integrated using the boundary conditions $t=0: q_{t}=0$, and $t=t, q_{t}=q_{t}$, the equation becomes

$$
\log \left(\mathbf{C} q_{e}-q_{t}\right)=\log q_{e}-\left(\frac{K_{1}}{2.303}\right) t
$$

From the pseudo-first-order model equation (3) above, $q_{e}$ and $q_{t}$ become the mass ratios of lead $(\mathrm{Pb})$ and zinc $(\mathrm{Zn})$ 
adsorbed at equilibrium at time $t(\mathrm{mg} / \mathrm{g})$, respectively, $t$ is the contact time ( $\mathrm{min})$, and $K_{1}$ is the pseudo-first-order rate constant (/min). A plot of equation (4) would give a straightline of $\log \left(q_{e}-q_{t}\right)$ against $t$ with $\log \left(q_{e}\right)$ as the intercept and the slope as $-\left(K_{1} / 2.303\right)$.

The pseudo-second-order equation is also given as

$$
\frac{\mathrm{d} q_{t}}{\mathrm{~d} t}=k_{2}\left(q_{e}-q_{t}\right)^{2}
$$

Using the same boundary conditions as in (2), the integration will give this equation

$$
\left(\frac{t}{q_{t}}\right)=\frac{1}{K_{2} q e^{2}}+\frac{1}{q_{e}} .
$$

This will also give a straight-line plot of $\left(t / q_{t}\right)$ in $(\mathrm{mg} / \mathrm{g})$ against $t$ (time.) with $\left(1 / q_{e}\right)$ as the slope and $\left(1 / K_{2} q e^{2}\right)$ as the intercept and $k_{2}$ is the second-order rate constant for the adsorption process.

Determination of the adsorption capacity of the zeolite for the ions in solution at various equilibrium concentrations $\left(C_{e}\right)$ was also achieved by evaluating the adsorption isotherm, commonly described by the Langmuir and/or Freundlich models which are represented by equations (7) and (8), respectively.

$$
\begin{gathered}
Q_{e}=\frac{Q_{\max } K_{L} C_{e}}{1+K_{L} C_{e}}, \\
Q_{e}=K_{F} C_{e}^{1 / n} .
\end{gathered}
$$

Equations (7) and (8) can be linearized to give the following equations:

$$
\begin{gathered}
\frac{C_{e}}{Q_{e}}=\frac{1}{K_{L} Q_{\max }}+\frac{C_{E}}{Q_{\max }}, \\
\log Q_{e}=\log K_{F}+\frac{1}{n} \log C_{e},
\end{gathered}
$$

where the Langmuir parameters are given by $Q_{\max }(\mathrm{mg}$ $\mathrm{Zn}^{2+} \mathrm{g}^{-1}$ or $\left.\mathrm{mg} \mathrm{Pb}^{2+} \mathrm{g}^{-1}\right)$ and $K_{L}\left(\mathrm{Lmg}^{-1} \mathrm{Zn}^{2+}\right.$ or $\mathrm{Lmg}^{-1}$ $\left.\mathrm{Pb}^{2+}\right)$ is the maximum capacity adsorption at high equilibrium concentrations and the equilibrium constant. The Freundlich parameters $K_{F}\left(\mathrm{mg} \mathrm{g}^{-1}\left(\mathrm{Lmg}^{-1}\right)^{1 / n} \mathrm{Zn}^{2+}\right.$ or $(\mathrm{mg}$ $\mathrm{g}^{-1}\left(\mathrm{Lmg}^{-1}\right)^{1 / n} \mathrm{~Pb}^{2+}$ and $(1 / n)$ are the Freundlich capacity factor and the Freundlich intensity parameter, respectively [36].

\section{Results and Discussion}

3.1. Fourier Transform Infrared Analysis of the Synthesized Zeolite. The FTIR analysis of the synthesized zeolite is shown in Figure 2. It has zeolitic vibrational bands [37, 38] with zeolite functional group which is present as a result of the bending vibrational mode of zeolitic water [39] and a very weak peak at $1630 \mathrm{~cm}^{-1}$. The strong peak at $1052 \mathrm{~cm}^{-1}$ shows asymmetric vibrations of the internal $\mathrm{T}-\mathrm{O}$ tetrahedron with a weak symmetric T-O stretching vibration recorded at $797 \mathrm{~cm}^{-1}$ similar to that observed by Katrick et al. and Zhang et al. [40, 41]. However, there was a very strong peak at $445 \mathrm{~cm}^{-1}$ as a result of the O-T-O bending vibration which confirms the presence of a five-membered structure as discussed by Sundraramurthy et al., 2000 [42].

3.2. X-Ray Diffraction Analysis. Analysis of Figure 3 shows that it has some dominant peaks which were observed at $2 \theta=8.09^{\circ}, 18.06^{\circ}, 19.78^{\circ}, 26.96^{\circ}, 21.56^{\circ}, 16.56^{\circ}, 26.96^{\circ}$, and $50.91^{\circ}$, respectively, which is similar to that synthesized by Anang et al. [43], a product identified as Zeolite Socony Mobil-11 (ZSM-11), which has a quartz phase [44] shown in blue at $2 \theta=21.56^{\circ}, 21.56^{\circ}, 26.96^{\circ}$, and $50.91^{\circ}$. The ZSM-11 phase was also designated as green was dominant at $8.09^{\circ}$ as also reported by [45].

3.3. Point of Zero Charge. The mechanism of adsorption depends on the $\mathrm{pH}$ of the solution and the $\mathrm{pH}_{\mathrm{PZC}}$ of the zeolite [46]. The surface is positively charged at $\mathrm{pH}<\mathrm{pHpzc}$ favoring the adsorption of anionic species and negatively charged at $\mathrm{pH}>\mathrm{pHpzc}$, which will favor the adsorption of cationic species [47]. The pHpzc of the adsorbent was found to be around 7 as shown in Figure 4 which is similar to the activated carbon used by Belhachemi et al., 2011.

\subsection{Percentage Removal/Reduction}

3.4.1. Analysis of Water Samples. The water samples taken from the various communities were analyzed and the result is presented in Table 1.

From Table 1, the result showed that most of the parameters measured were within the values for GSA except sulfate and phosphate. After two (2) hours of treatment with the synthesized zeolite, the change in values for the two parameters is presented in Table 2 and their percentage removal/reduction was calculated and graphically presented in Figures 5 and 6.

The percentage reduction in the nitrate and phosphate concentration was presented graphically in Figures 5 and 6. The percentage reduction in nitrate concentration as shown in Figure 4 was very high for Amoyaw followed by Apewosika, Amamoma, Kwaprow, Ebubonko, and Abura with values of $76.2 \%, 63.2 \%, 60.5 \%, 60.4 \%, 40 \%$, and $36.7 \%$, respectively. The phosphate concentration also showed a reduction as shown in Figure 5 with the highest percentage reduction with Ebubonko recording a 96.1\% reduction followed by Abura (95.7\%), Amoyaw (93\%), Amamoma (93\%), and Apewosika (92.5\%).

3.4.2. Analysis of $\mathrm{Pb}^{2+}$ and $\mathrm{Zn}^{2+}$ Removal/Reduction. The effect of the mass of adsorbent with time on the percentage removal of $\mathrm{Pb}^{2+}$ and $\mathrm{Zn}^{2+}$ concentrations is shown in Figures 7 and 8. In Figure 7, the mass of adsorbent used was $1.0 \mathrm{~g}$ with a treatment time of 5 hours. The maximum percentage removal/reduction of $\mathrm{Zn}^{2+}$ and $\mathrm{Pb}^{2+}$ achieved was $90.57 \%$ and $86.61 \%$, respectively, after 4 hours of treatment. 


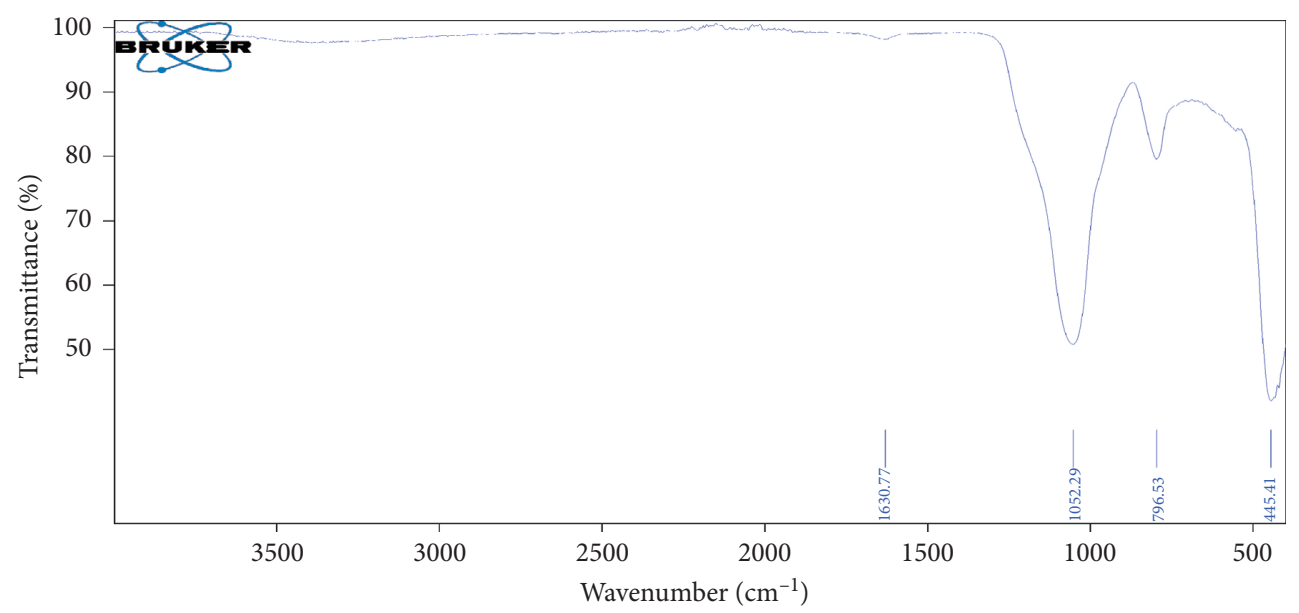

Figure 2: Fourier transform infrared analysis of synthesized zeolite (ZSM-11).

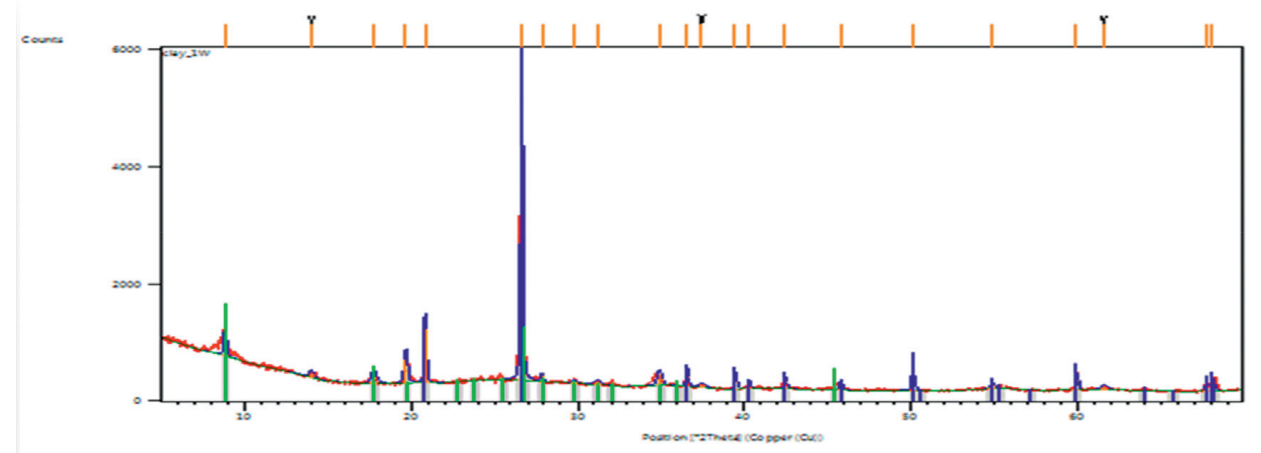

Figure 3: X-ray diffraction spectrum of synthesized ZSM-11.

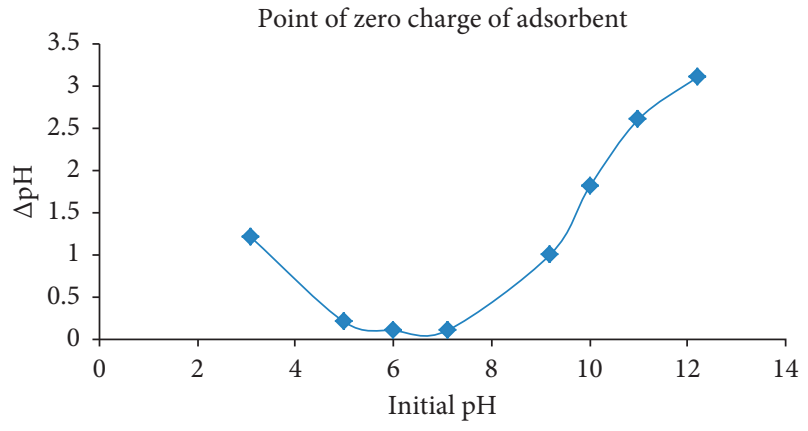

FIgURE 4: A graph of $\Delta \mathrm{pH}$ against initial $\mathrm{pH}$.

Considering an increase in the mass of adsorbent $(1.5 \mathrm{~g})$, the percentage reduction calculated for $\mathrm{Zn}^{2+}$ and $\mathrm{Pb}^{2+}$ was 93.26\% and 89.36\%, respectively, as shown in Figure 8 and the maximum reduction was also recorded at after 4 hours of treatment.

It can, therefore, be concluded that an increase in the mass of the adsorbent caused an increase in the percentage removal of the ions in solution.

3.4.3. Kinetics of the Reduction Process. The pseudo-firstorder kinetics was determined to assess the feasibility of the reaction.
The pseudo-first-order reaction kinetics is graphically presented in Figure 9. The $R^{2}$ values for the reaction were found to be 0.9929 and 0.8503 , respectively, for $\mathrm{Zn}^{2+}$ and $\mathrm{Pb}^{2+}$ with their pseudo-first-order adsorption rate constants $K_{1}\left(\mathrm{~min}^{-1}\right)$ values of $0.006909 \mathrm{~min}^{-1}$ and $0.010594 \mathrm{~min}^{-1}$ as shown in Table 3. This implies that the reduction in the concentration of $\mathrm{Zn}^{2+}$ favors the first-order reaction compared to $\mathrm{Pb}^{2+}$.

The pseudo-second-order kinetics of the process was also determined and the $R^{2}$ values were 0.9662 and 0.6912 , respectively, for $\mathrm{Zn}^{2+}$ and $\mathrm{Pb}^{2+}$ as depicted in Table 4. Their pseudo-second-order adsorption reaction constants $K_{2}$ $\left(\mathrm{g} \cdot \mathrm{mg}^{-1} \cdot \mathrm{min}^{-1}\right)$ were 0.003255 and 0.000446 for $\mathrm{Zn}^{2+}$ and $\mathrm{Pb}^{2+}$.

The values for the pseudo-second-order reaction are also graphically presented in Figure 10.

The adsorption isotherms for Langmuir and Freundlich models for zinc and lead were also evaluated to assess the adsorption capacity of the zeolite. This can be seen in Table 5 which shows the summary of the adsorption isotherm parameters.

Table 5 gives a summary of the adsorption isotherms of zinc and lead to the surface of the synthesized zeolite. Considering the Freundlich model as represented in Figure 11 , the $R^{2}$ values for $\mathrm{Zn}^{2+}$ and $\mathrm{Pb}^{2+}$ were derived to be 
TABle 1: Physicochemical parameters of water samples taken from some communities within the Cape Coast metropolis in the central region of Ghana.

\begin{tabular}{lccccccccc}
\hline Parameters & Units & Abura & Kwaprow & Apewosika & Amamoma & Ebubonko & Amoyaw & GSA values & WHO values \\
\hline $\mathrm{pH} @ 25^{\circ} \mathrm{C}$ & & 6.8 & 6.98 & 5.31 & 5.96 & 5.98 & 6.23 & \\
Turbidity & $\mathrm{NTU}$ & 2.4 & 2.6 & 2.5 & 2.6 & 2.2 & 2.4 & 5 or less & 50 or less \\
Total dissolved solids & $\mathrm{NTU}$ & 151 & 253 & 230 & 270 & 220 & 240 & 1000 & 300 or less \\
Total hardness & $\mathrm{mgL}^{-1}$ & 173 & 150 & 130 & 120 & 118 & 74 & 500 & 2500 \\
Conductivity & $\mu \mathrm{S} \cdot \mathrm{cm}^{-1}$ & 570 & 590 & 853 & 748 & 1044 & 875 & 2500 \\
Nitrate content & $\mathrm{mgL}^{-1}$ & 23.7 & 50.5 & 54.4 & 55.7 & 28.3 & 126 & $45-50$ & 50 \\
Phosphate content & $\mathrm{mgL}^{-1}$ & 0.69 & 0.5 & 0.67 & 0.72 & 1.03 & 0.64 & $0.005-0.05$ & $0.005-0.05$ \\
Chlorides as Cl- & $\mathrm{mgL}^{-1}$ & 195 & 96 & 0 & 100 & 89 & 87 & 250 & $<0.01$ \\
Sulfate as $\mathrm{SO}_{4}{ }^{2-}$ & $\mathrm{mgL}^{-1}$ & 0 & 0 & 0 & 0 & 0 & 0 & 200 & $0-0.01$ \\
\hline
\end{tabular}

TABLE 2: The percentage reduction in the concentration of water samples from the communities.

\begin{tabular}{lcccccccccccccccc}
\hline \multirow{2}{*}{ Parameter } & Units & \multicolumn{2}{c}{ Abura } & \multicolumn{2}{c}{ Kwaprow } & \multicolumn{2}{c}{ Apewosika } & \multicolumn{2}{c}{ Amamoma } & \multicolumn{2}{c}{ Ebubonko } & \multicolumn{2}{c}{ Amoyaw } & GSA & WHO \\
vefore & After & Before & After & Before & After & Before & After & Before & After & Before & After & values & values \\
\hline $\begin{array}{l}\text { Nitrate } \\
\text { content }\end{array}$ & $\mathrm{mgL}^{-1}$ & 23.7 & 15 & 50.5 & 20 & 54.4 & 20 & 55.7 & 22 & 28.3 & 17 & 126 & 30 & $45-50$ & 50 \\
\hline $\begin{array}{l}\text { Phosphate } \\
\text { content }\end{array}$ & $\mathrm{mgL}^{-1}$ & 0.69 & 0.03 & 0.5 & 0.04 & 0.67 & 0.05 & 0.72 & 0.05 & 1.03 & 0.04 & 0.64 & 0.04 & $0.005-0.05$ & $0.005-0.05$ \\
\hline
\end{tabular}

0.7576 and 0.7183 . It was realized that the $(1 / n)$ values for $\mathrm{Zn}^{2+}$ and $\mathrm{Pb}^{2+}$ are 0.795 and 0.642 , respectively, and these values are less than one $(1 / n<1)$.

The Langmuir isotherm model for the adsorption process gave $R^{2}$ values of 0.1742 and 0.3350 for $\mathrm{Zn}^{2+}$ and $\mathrm{Pb}^{2+}$, respectively, as seen in Figure 12. These $R^{2}$-values are very low and together with other factors such as the average of the triplicate data and the sorption mechanism may have contributed to the negative values of $Q_{\max }$.

The adsorption isotherm becomes favorable for $(1 / n)<1$ (or $n>1)$, unfavorable for $(1 / n)>1($ or $<1)$, and linear or $n=1$ [36]. This implies that the adsorption of zinc and lead follows the Freundlich model and not the Langmuir model and the low values of $R_{L}$ and $R_{F}$ indicate high and favorable adsorption of adsorbate onto adsorbates as determined by Belhachemi et al., 2011 [46].

\subsection{Photodegradation Process}

3.5.1. Mechanism of Degradation. The mechanism for the photodegradation of rhodamine blue and methyl orange dyes was studied and observed to have occurred under two different mechanisms. The first process starts with the illumination of the zeolite which results in the excitation of a photon with energy greater than the bandgap between the valance and conduction bands as shown by [48]

$$
\begin{gathered}
\frac{\mathrm{MO}}{\mathrm{RB}}+h v \longrightarrow \frac{\mathrm{MO}}{\mathrm{RB}}\left(e_{\mathrm{CB}}^{-}+h_{\mathrm{VB}}^{+}\right), \\
h_{\mathrm{VB}}^{+}+\text {dye } \longrightarrow \text { dye } * \longrightarrow \text { dye degradation. }
\end{gathered}
$$

The excited electron leaves a corresponding hole which is highly oxidative. The photoinduced hole $(h+)$ and the formed hydroxyl radical $(\mathrm{OH}-)$ oxidize the dye

$$
\begin{gathered}
h_{\mathrm{VB}}^{+}+\mathrm{H}_{2} \mathrm{O} \longrightarrow \mathrm{H}++\mathrm{OH} . \\
h_{\mathrm{VB}}^{+}+\mathrm{OH}-\longrightarrow \mathrm{OH} .
\end{gathered}
$$

The second step is the sensitization where the dyes undergo a radicalization process to give mineralized products $[49,50]$. These two mechanisms can be shown in Figure 13.

The drastic change in concentration of dye with time was very sharp for the first $30 \mathrm{~min}$ of the degradation time for $\mathrm{RhB}$ compared to MO as seen in Figures 14 and 15.

Figure 14 shows that there was a sharp decrease in the concentration of rhodamine blue compared to methyl orange within the first $30 \mathrm{~min}$ by $61 \%$ to $38.3 \%$, respectively, as shown in Figure 15. The changes in the concentrations continued with a further decrease from $75 \%$ to $90 \%$ after the $60 \mathrm{~min}$ to the $180 \mathrm{~min}$ for rhodamine blue and $47.73 \%$ to $67.3 \%$, respectively.

3.5.2. Kinetics of Degradation. The kinetics of the dye degradation process was monitored by their pseudo-firstand second-order reactions.

From Figure 16, it was realized that the $R^{2}$ values were 0.9376 and 0.9737 , respectively, for methyl orange and rhodamine blue. The pseudo-first-order degradation constant $\left(K_{1}\right)$ was observed to be 0.03 and 0.02 with the $q_{e}$ calculated values to be 1.303 and 1.13, respectively, for rhodamine blue and methyl orange and $q_{e}$ experimental values of 1.38 and 1.06, respectively, as shown in Table 6. 


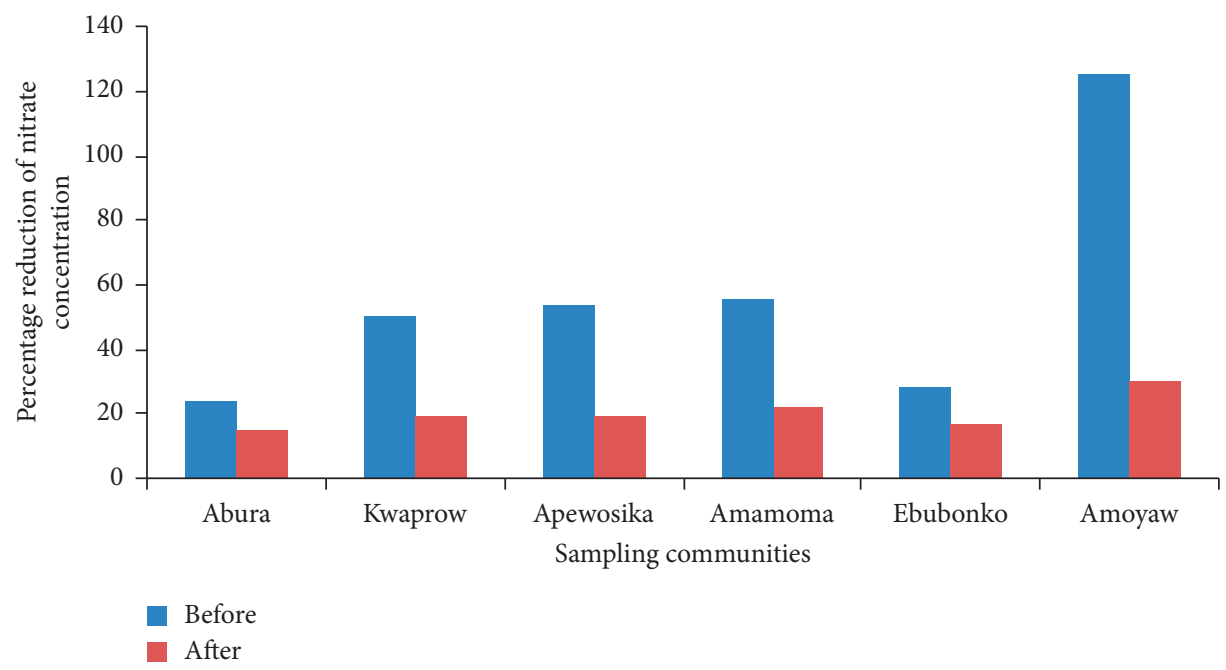

FIGURE 5: A graph of percentage reduction in nitrate concentration after two hours of treatment with ZSM-11.

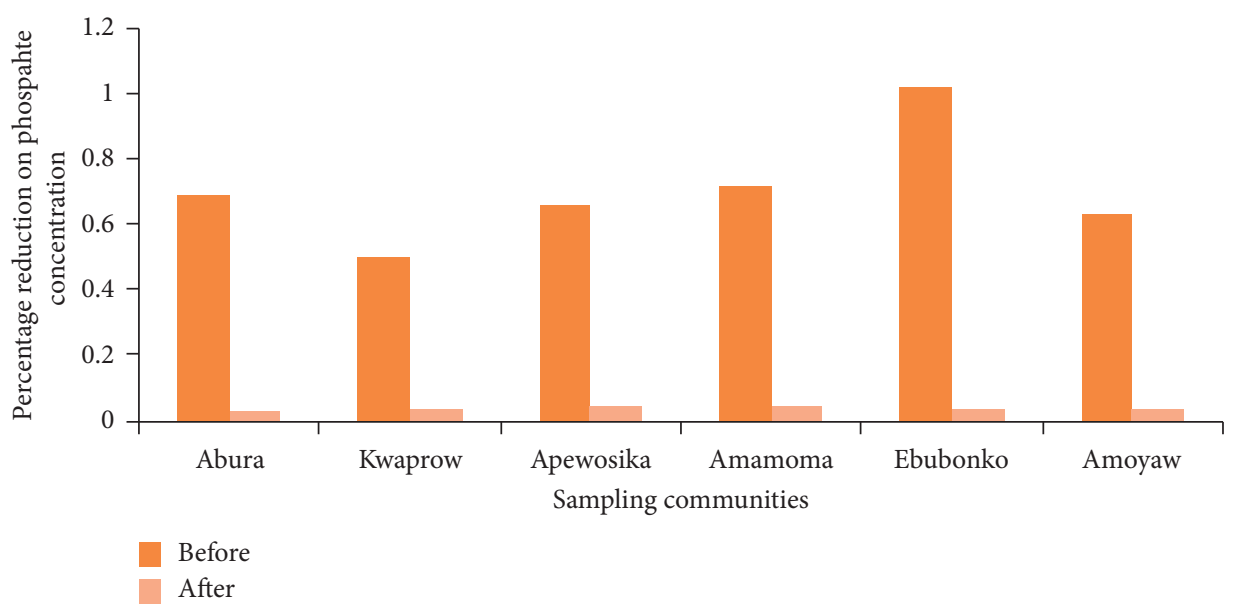

FIGURE 6: A graph of percentage reduction in phosphate concentration after two hours of treatment with ZSM-11.

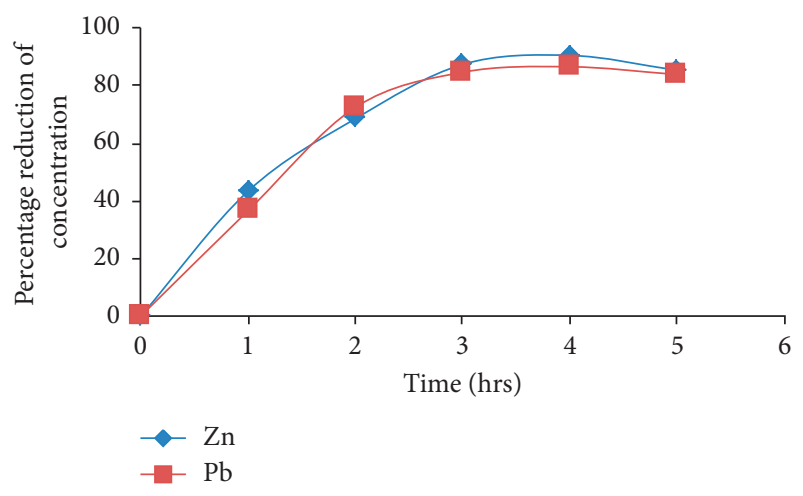

FIGURE 7: Effect of $1.0 \mathrm{~g}$ mass of ZSM-11 on the removal of $\mathrm{Pb}^{2+}$ and $\mathrm{Zn}^{2+}$ from aqueous solutions.

This shows a good relationship between the calculated and experimental values. It also indicates that the adsorption process was very effective.

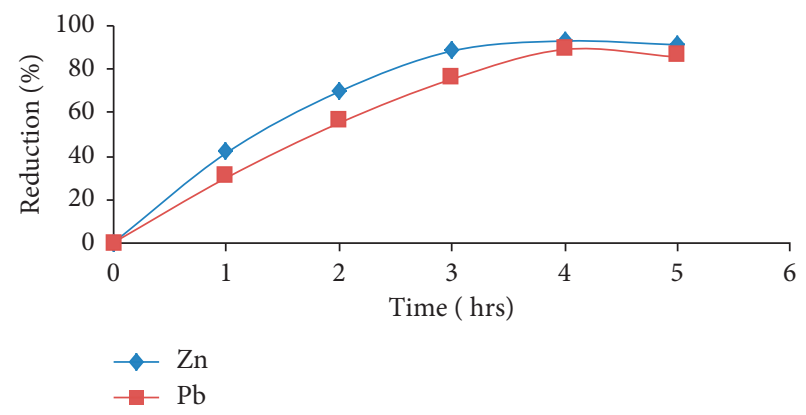

FIGURE 8: Effect of $1.5 \mathrm{~g}$ ZSM-11 on the removal of $\mathrm{Pb}^{2+}$ and $\mathrm{Zn}^{2+}$ from aqueous solutions.

Similarly, the pseudo-second-order also showed degradation constant of 0.035 and 0.021 for rhodamine blue and methyl orange, respectively. The mass ratio $\left(q_{e}\right)$ of the dyes at equilibrium was 1.50 and 1.23 as shown in Table 7 . 


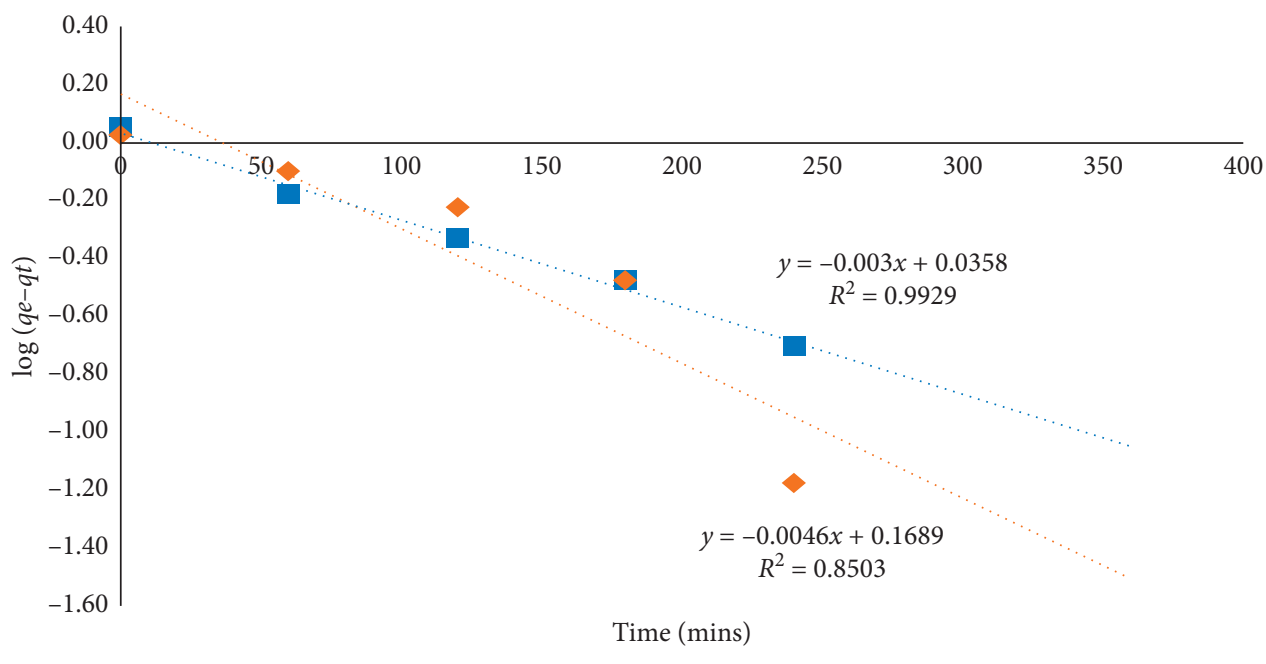

$\mathrm{Zn}$

$\mathrm{Pb}$

FIGURE 9: A graph of the pseudo-first-order kinetics for the removal of $\mathrm{Zn}^{2+}$ and $\mathrm{Pb}^{2+}$ from solution.

TABLE 3: A summary of the pseudo-first-order reaction kinetic model parameters.

\begin{tabular}{lccc}
\hline Sample & $R^{2}$ & $K_{1}\left(\mathrm{~min}^{-1}\right)$ & Qe $(\mathrm{mg} / \mathrm{g})$ \\
\hline $\mathrm{Zn}^{2+}$ & 0.9929 & 0.006909 & 1.085925 \\
$\mathrm{~Pb}^{2+}$ & 0.8503 & 0.010594 & 1.475367 \\
\hline
\end{tabular}

TABLE 4: A summary of the pseudo-second-order reaction kinetic model parameters.

\begin{tabular}{lccc}
\hline Sample & $R^{2}$ & $K_{2}\left(\mathrm{~min}^{-1}\right)$ & Qe $(\mathrm{mg} / \mathrm{g})$ \\
\hline $\mathrm{Zn}^{2+}$ & 0.9662 & 0.003255 & 1.70503 \\
$\mathrm{~Pb}^{2+}$ & 0.6912 & 0.000446 & 3.33667 \\
\hline
\end{tabular}

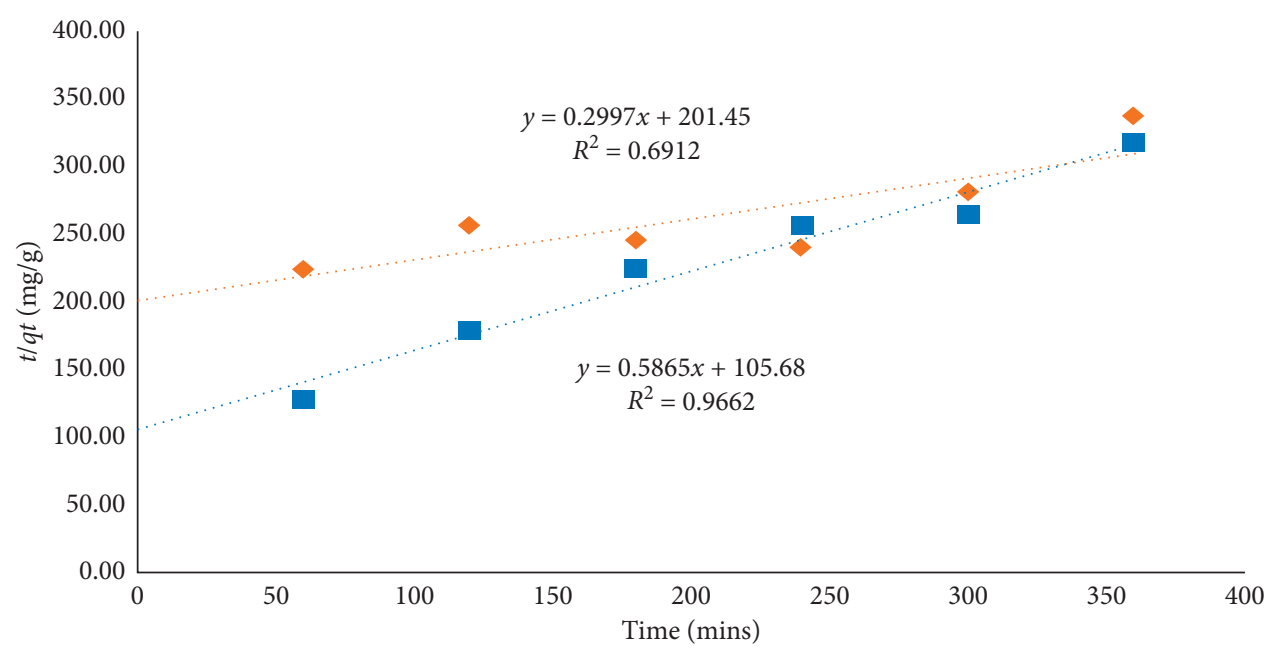

$\mathrm{Zn}$

$\mathrm{Pb}$

FIGURE 10: A graphical presentation of the pseudo-second-order reaction kinetic model. 
TABLE 5: Adsorption isotherms parameters for zinc and lead to ZSM-11.

\begin{tabular}{lcccrr}
\hline & \multicolumn{2}{c}{ Freundlich } & \multicolumn{2}{c}{ Langmuir } \\
Samples & $K_{f}\left(\mathrm{Lmg}^{-1}\right)\left(\mathrm{mg} \mathrm{g}^{-1}\right)$ & $(1 / n)$ & $R^{2}$ & $K_{L}\left(\mathrm{Lmg}^{-1}\right)$ & $Q_{\max }\left(\mathrm{mg} \mathrm{g}^{-1}\right)$ \\
\hline Zinc & 12.42 & 0.795 & 0.7576 & - & -217.391 \\
Lead & 6.45 & 0.642 & 0.7183 & -105.263 & 0.1742 \\
\hline
\end{tabular}

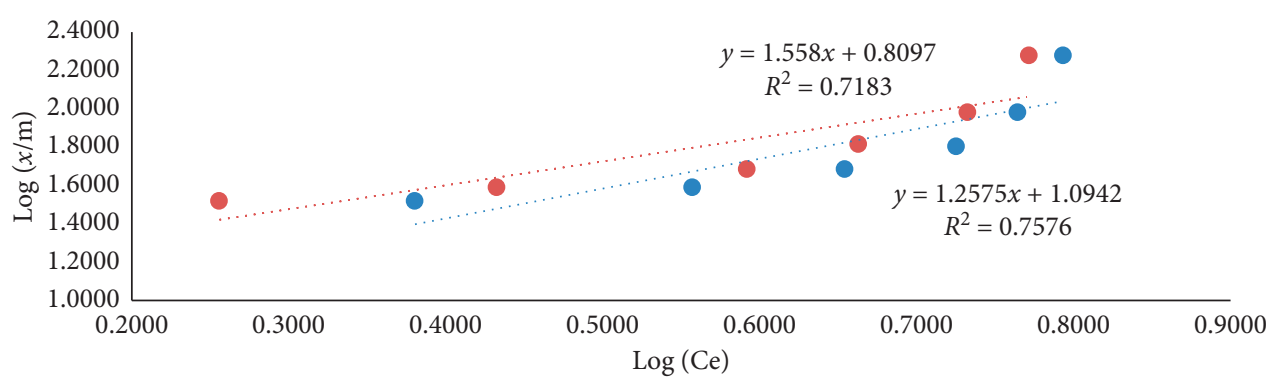

$\mathrm{Zn}$

$\mathrm{Pb}$

Figure 11: Freundlich isotherm of $\mathrm{ZSM}-11$ on $\mathrm{Pb}^{2+}$ and $\mathrm{Zn}^{2+}$ removal from aqueous solution.

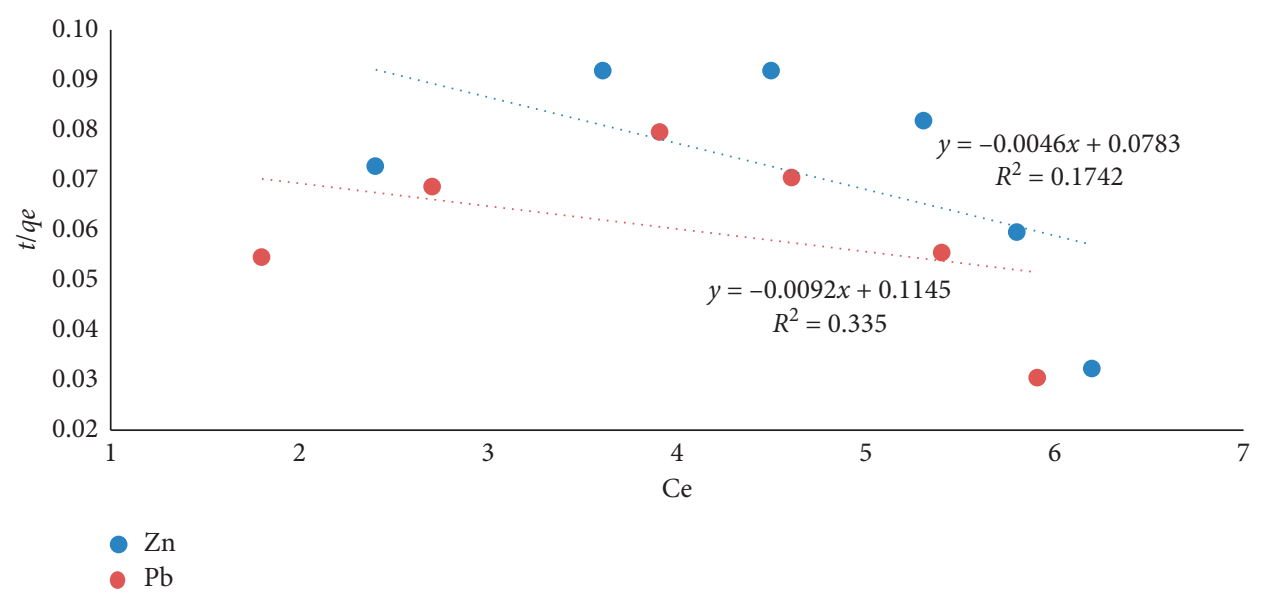

FIGURE 12: Langmuir adsorption isotherm for $\mathrm{Pb}^{2+}$ and $\mathrm{Zn}^{2+}$ concentration reduction by ZSM-11.

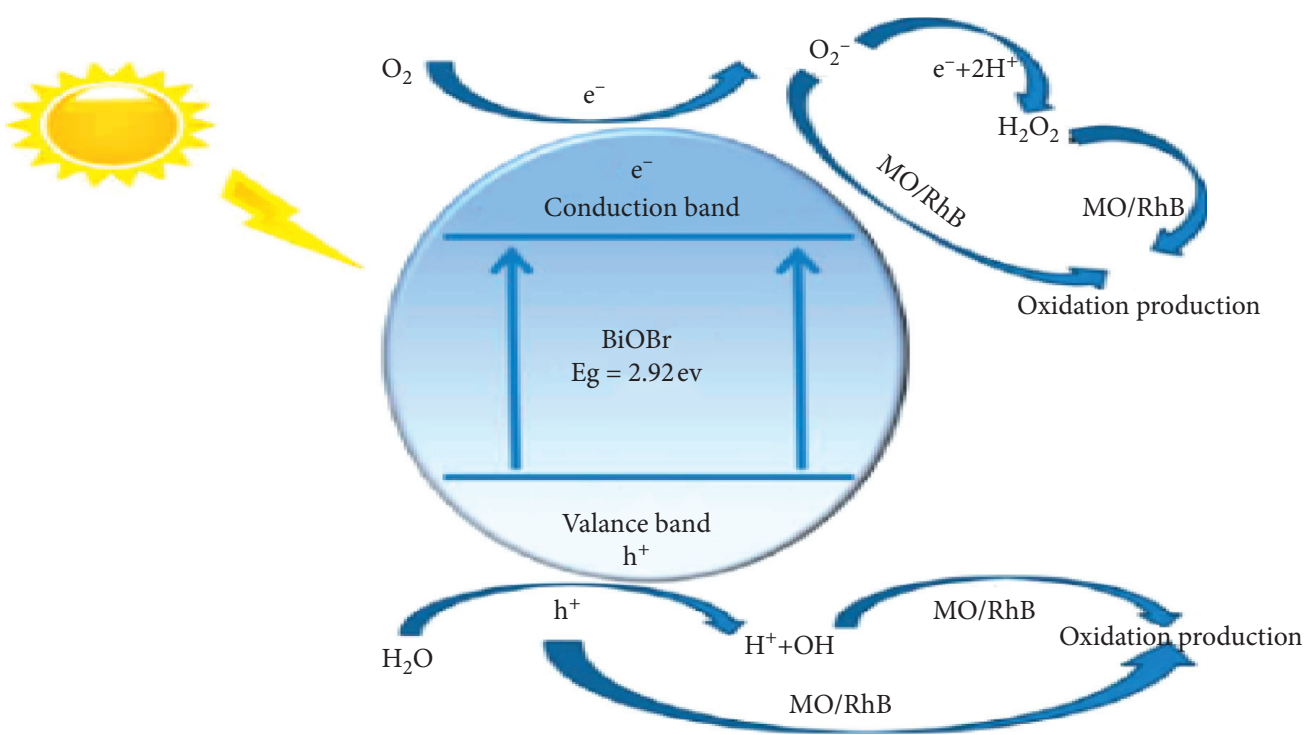

FIGURE 13: Schematics of photodegradation of dyes in solar irradiation [51]. 


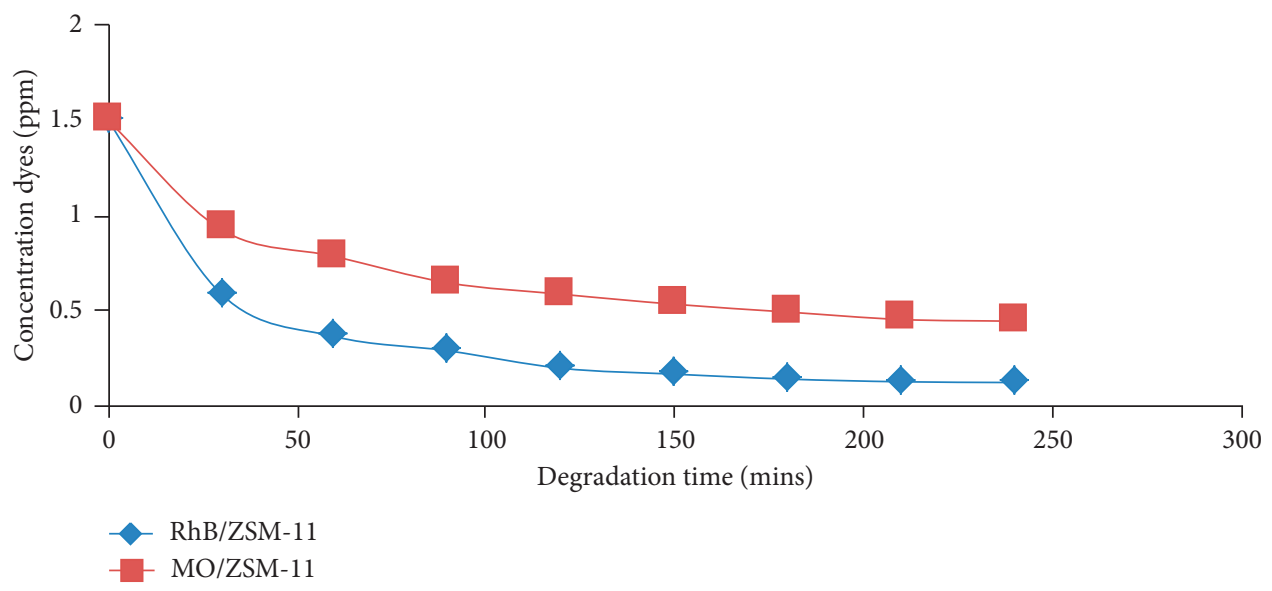

FIGURE 14: A photodegradation process of rhodamine blue and methyl orange showing the change in concentration with time.

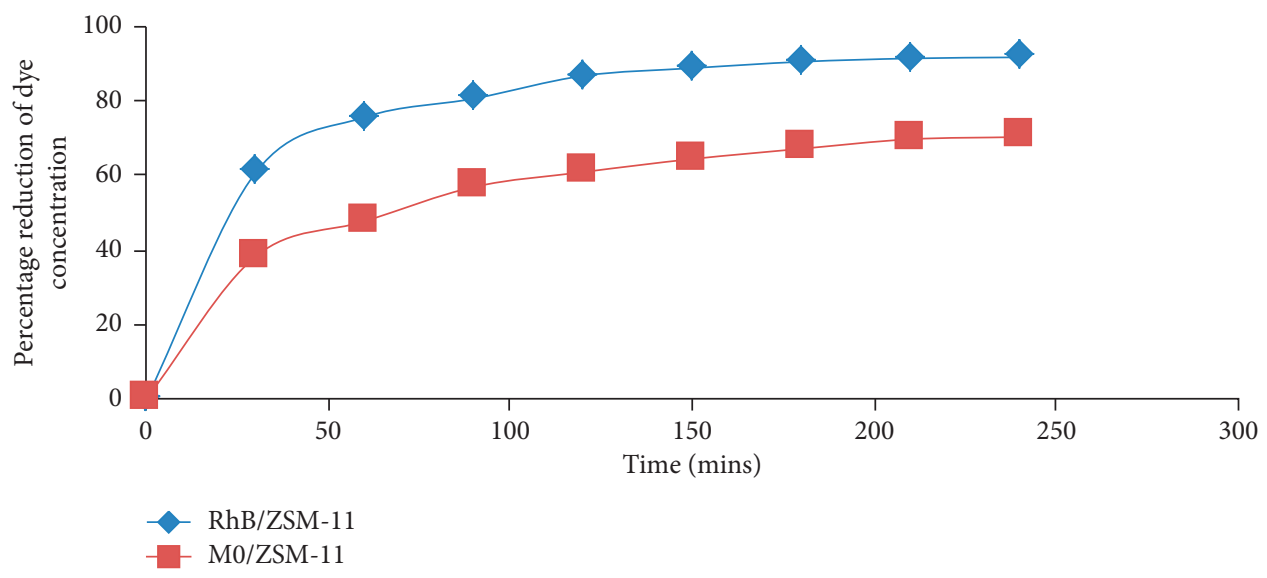

Figure 15: A graph showing the percentage reduction of dyes with time.

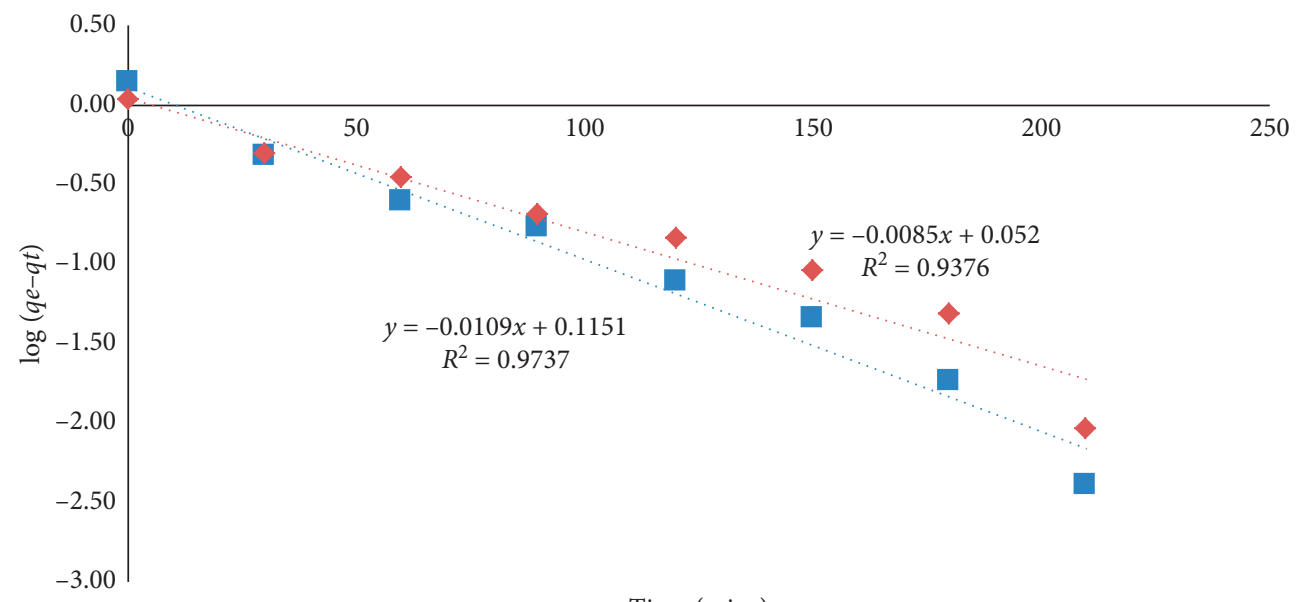

Time (mins)

- Rhodamine blue (mg/L)

- Methyl orange $(\mathrm{mg} / \mathrm{L})$

FIGURE 16: A pseudo-first-order degradation process for rhodamine blue and methyl orange. 
TABLE 6: A summary of pseudo-first-order degradation process model parameters.

\begin{tabular}{lcc}
\hline & Rhodamine & Methyl orange \\
\hline$k_{1}$ & 0.03 & 0.02 \\
Qe (model) & 1.303 & 1.13 \\
Qe (experimental) & 1.38 & 1.06 \\
\hline
\end{tabular}

TABLE 7: A table of pseudo-second-order kinetics for the degradation of rhodamine blue and methyl orange.

\begin{tabular}{lcc}
\hline & Rhodamine & Methyl \\
\hline$q_{e}$ & 1.50 & 1.23 \\
$k_{2}$ & 0.035 & 0.021 \\
$h$ & 0.078 & 0.031 \\
\hline
\end{tabular}

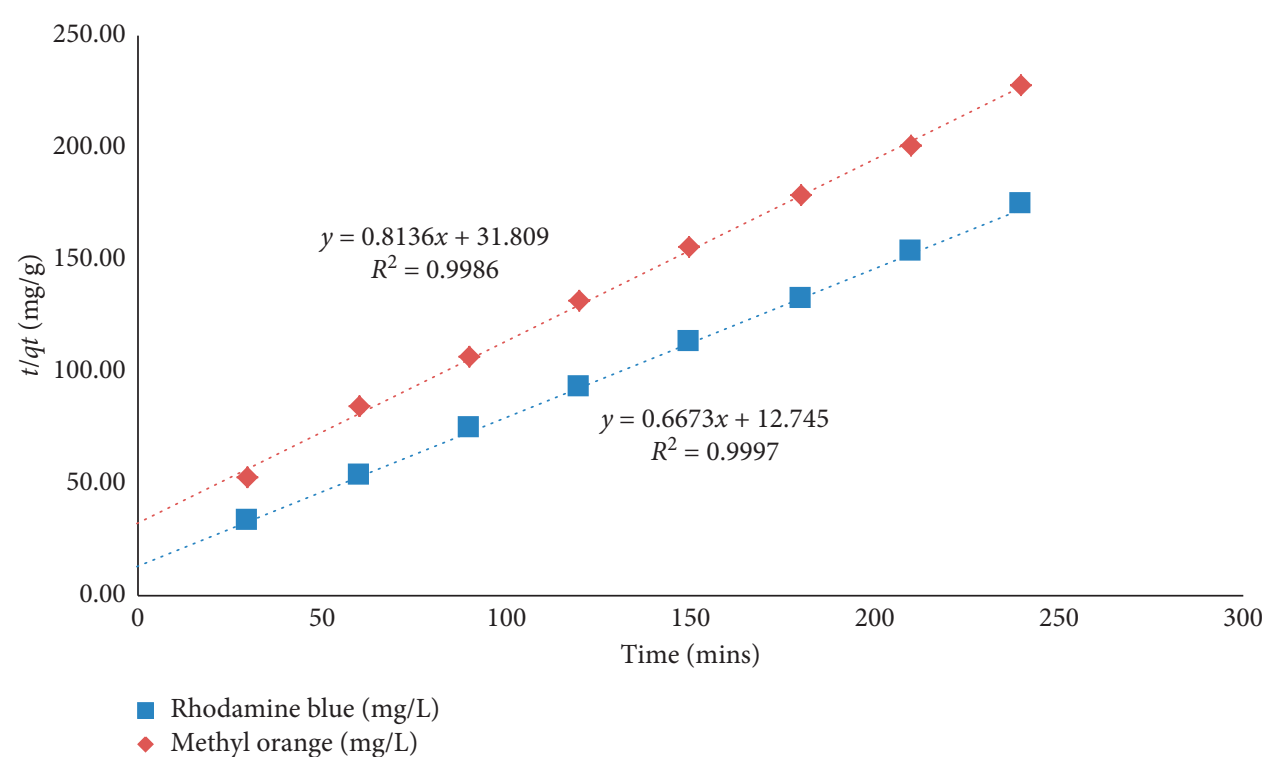

Figure 17: Pseudo-second-order degradation reaction of rhodamine blue and methyl orange.

The pseudo-second-order reaction constant $\left(K_{2}\right)$ was found to be 0.035 and 0.021 , respectively, for rhodamine blue and methyl orange with $R^{2}$ values of 0.9986 and 0.9997 for rhodamine blue and methyl orange as shown in Figure 17.

This implies the photodegradation of rhodamine blue and methyl orange using laboratory synthesized ZSM-11 under sunlight favors the pseudo-second-order kinetic process.

\section{Conclusion}

ZSM-11 was synthesized using rice husk and was characterized using the FTIR and the X-ray diffraction. The point of zero charge of the zeolite was also determined. It was used to treat underground water samples from some communities within the Cape Coast metropolis in the central region of Ghana. It was also used to remove some heavy metals, namely, $\mathrm{Pb}^{2+}$ and $\mathrm{Zn}^{2+}$, from laboratory prepared aqueous solutions. The synthesized zeolite was also used to photodegrade rhodamine blue and methyl orange. In all these applications, it was found to be very effective and can be used industrially when scaled-up.

\section{Data Availability}

All the data concerning this research work are with the authors.

\section{Conflicts of Interest}

There are no conflicts of interest regarding this research work.

\section{Acknowledgments}

The authors want to acknowledge the role of the technicians at the Chemistry Laboratory of the Department of Chemistry at the University of Cape Coast. This research work was funded by the authors involved.

\section{References}

[1] X. Yin, Z. Li, S. Wang, N. Chu, J. Yang, and J. Wang, "Hydrothermal synthesis of hierarchical zeolite Taggregates using tetramethylammonium hydroxide as single template," 
Microporous and Mesoporous Materials, vol. 201, pp. 247-257, 2015.

[2] X. Querol, N. Moreno, J. C. Umaña et al., "Synthesis of zeolites from coal fly ash: an overview," International Journal of Coal Geology, vol. 50, no. 1-4, pp. 413-423, 2002.

[3] C. C. Kwakye-Awuah, C. Williams, M. A. Kenward, and I. Radecka, "Antimicrobial action and efficiency of silverloaded zeolite X," Journal of Applied Microbiology, vol. 104, no. 5, pp. 1516-1524, 2008.

[4] W. Mozgawa, M. Król, and K. Barczyb, "FT-IR studies of zeolites from different structural groups," CHEMIK, vol. 65, no. 7, pp. 667-674, 2011.

[5] P. Xie, Y. Luo, Z. Ma et al., "Catalytic decomposition of $\mathrm{N}_{2} \mathrm{O}$ over Fe-ZSM-11 catalysts prepared by different methods: nature of active Fe species," Journal of Catalysis, vol. 330, pp. 311-322, 2015.

[6] L. Mang, Desalination, and Water Treatment, Taylor \& Francis, Abingdon, England, 2014.

[7] G. T. Kokotailo, "Crystalline zeolite product constituting ZSM-5/ZSM-11 intermediates,” Patent No: 4, vol. 229, p. 424, 1980.

[8] K. Zhang, Y. Liu, J. Zhao, and C. Liu, "Hierarchical porous ZSM-5 zeolite synthesized by in situZeolitization and its coke deposition resistance in aromatization reaction," Chinese Journal of Chemistry, vol. 30, no. 3, pp. 597-603, 2012.

[9] P. D. Kartick, G. Sourav, and K. N. Milan, "A facile synthesis of ZSM-11 zeolite particles using rice husk ash as silica source," Materials Letter, vol. 87, pp. 87-89, 2012.

[10] S. Affandi, H. Setyawan, S. Winardi, A. Purwanto, and R. Balgis, "A facile method for production of high-purity silica xerogels from bagasse ash," Advanced Powder, vol. 20, no. 5, pp. 468-472, 2009.

[11] M. A. Barakat, "New trends in removing heavy metals from industrial wastewater," Arabian Journal of Chemistry, vol. 4, no. 4, pp. 361-377, 2010.

[12] A. Demirak, F. Yilmaz, A. Levent Tuna, and N. Ozdemir, "Heavy metals in water, sediment and tissues of Leuciscus cephalus from a stream in southwestern Turkey," Chemosphere, vol. 63, no. 9, pp. 1451-1458, 2006.

[13] P. Chanpiwat, S. Sthiannopkao, and K.-W. Kim, "Metal content variation in wastewater and biosludge from Bangkok's central wastewater treatment plants," Microchemical Journal, vol. 95, no. 2, pp. 326-332, 2010.

[14] S. Muhammad, M. Tahir Shah, and S. Khan, "Arsenic health risk assessment in drinking water and source apportionment using multivariate statistical techniques in Kohistan region, Northern Pakistan," Food and Chemical Toxicology, vol. 48, no. 10, pp. 2855-2864, 2010.

[15] A. Asfaram, M. Ghaedi, A. Goudarzi, and M. Rajabi, "Response surface methodology approach for optimization of simultaneous dye and metal ion ultrasound-assisted adsorption onto Mn-doped $\mathrm{Fe}_{3} \mathrm{O}_{4}$-NPs loaded on AC: kinetic and isothermal studies," Dalton Transactions, vol. 44, pp. 14707-14723, 2015.

[16] Z. Yiming, S. Fu, H. Liu, S. Yang, and H. Zhan, "Removal of methylene blue dyes from wastewater using cellulose-based super adsorbent hydrogels," Polymer Engineering \& Science, vol. 51, no. 12, pp. 2417-2424, 2011.

[17] A. Pandey, D. Bera, A. Shukla, and R. Lalitagauri, "Potential of agarose for biosorption of $\mathrm{Cu}$ (II) in aqueous system," American Journal of Biochemistry and Biotechnology, vol. 3, no. 2, pp. 55-59, 2007.

[18] A. K. Meena, K. Kadirvelu, G. K. Mishra, C. Rajagopal, and P. N. Nagar, "Adsorptive removal of heavy metals from aqueous solution by treated sawdust (Acacia arabica)," Journal of Hazardous Materials, vol. 150, pp. 604-611, 2008.

[19] S. S. Ahluwalia and D. Goyal, "Removal of heavy metals from waste tea leaves from aqueous solution," Engineering in Life Sciences, vol. 5, pp. 158-162, 2005.

[20] M. N. Chong, B. Jin, C. W. K. Chow, and C. Saint, "Recent developments in photocatalytic water treatment technology: a review," Water Resources Management, vol. 44, pp. 29973027, 2010.

[21] T. A. Khan, S. A. Chaudhry, and I. Ali, "Thermodynamic and kinetic studies of As (V) removal from water by zirconium oxide-coated marine sand," Environmental Science and Pollution Research, vol. 20, pp. 5425-5440, 2013.

[22] S. Dashamiri, M. Ghaedi, K. Dashtian, M. Reza Rahimi, A. Goudarzi, and R. Jannesar, "Ultrasonic enhancement of the simultaneous removal of quaternary toxic organic dyes by $\mathrm{CuO}$ nanoparticles loaded on activated carbon: central composite design, kinetic, and isotherm study," Ultrason Sonochem, vol. 31, pp. 546-557, 2016.

[23] M. Umar and H. Abdul Aziz, "Photocatalytic degradation of organic pollutants in water," in Organic Pollutants-Monitoring, Risk, and Treatment, pp. 195-208, IntechOpen, London, UK, 2013.

[24] D. E. Gomez, D. Amutha Rani, C. R. Cheeseman, D. Deegan, M. Wise, and A. R. Boccaccini, "Thermal plasma technology for the treatment of wastes: a critical review," Journal of Hazardous Materials, vol. 161, no. 2-3, pp. 614-626, 2009.

[25] A. Babuponnusami and K. Muthukumar, "A review on Fenton and improvements to the Fenton process for wastewater treatment," Journal of Environmental Chemical Engineering, vol. 2, no. 1, p. 557, 2014.

[26] S. B. Martínez, J. Pérez-Parra, and R. Suay, "Use of ozone in wastewater treatment to produce water suitable for irrigation," Water Resources Management, vol. 25, p. 2109, 2011.

[27] D. H. Bremner, "Degradation of phenolic aqueous solutions by high frequency Sono-Fenton systems," Applied Catalysis B, vol. 90, no. 3-4, pp. 380-388, 2009.

[28] A. Shoumkova, Zeolites for Water and Wastewater Treatment: An Overview, Australian Institute of High Energetic Materials (ABN 68126426 917), Sippy Downs, Queensland, Australia, 2014.

[29] N. Moazezi, M. Baghdadi, M. A. Hickner, and M. A. Moosavian, "Modeling and experimental evaluation of $\mathrm{Ni}$ (II) and $\mathrm{Pb}$ (II) sorption from aqueous solutions using a polyaniline/CoFeC ${ }_{6} \mathrm{~N}_{6}$ nanocomposite," Journal of Chemical \& Engineering Data, vol. 63, no. 3, pp. 741-750, 2018.

[30] G. Temesgen, S. Dube, V. Mhuka, and M. M. Nindi, "Bioremediation of $\mathrm{Cd}$ (II), $\mathrm{Pb}$ (II), and $\mathrm{Cu}$ (II) from industrial effluents by Moringa stenopetala seed husk," Journal of Environmental Science and Health, Part A.vol. 54, no. 4, pp. 337-351, 2019.

[31] M. M. Mohamed, F. I. Zidan, and M. Thabet, "Synthesis of ZSM-5 zeolite from rice husk ash: characterization and implications for photocatalytic degradation catalysts," Microporous and Mesoporous Materials, vol. 108, pp. 193-203, 2008.

[32] F.-W. Chang, "Ethanol dehydrogenation over copper catalysts on rice husk ash prepared by ion exchange," Applied Catalysis A: General, vol. 304, pp. 30-39, 2006.

[33] K. Bourikas, J. Vakros, C. Kordulis, and A. Lycourghiotis, "Potentiometric mass titrations: experimental and theoretical establishment of a new technique for determining the point of zero charge (PZC) of metal (Hydr) oxides," The Journal of Physical Chemistry B, vol. 107, pp. 9441-9451, 2003. 
[34] M. Gao, D. Zhang, X. Pu et al., "BiOBr photocatalysts with tunable exposing proportion of $\{001\}$ facets: combustion synthesis, characterization, and high visible-light photocatalytic properties," Materials Letters, vol. 140, pp. 31-34, 2015.

[35] A. A. Michael, O. P. Michael, and O. B. Kwasi, "Extraction and characterisation of african star apple (Chrysophyllum albidum) seed oil and the adsorptive properties of the fruit shell in Ghana," Hindawi International Journal of Food Science, vol. 2019, Article ID 4959586, 8 pages, 2019.

[36] B. Kwakye-Awuah, B. Sefa-Ntiri, E. Von-Kiti, I. Nkrumah, and C. Williams, "Adsorptive removal of iron and manganese from groundwater samples in Ghana by zeolite Y synthesized from Bauxite and Kaolin," MDPA-Water, vol. 11, no. 9, p. 1912, 2019.

[37] M. Alkan, Ç. Hopa, Z. Yilmaz, and H. Güler, "The effect of alkali concentration and solid/liquid ratio on the hydrothermal synthesis of zeolite $\mathrm{NaA}$ from natural kaolinite," Microporous and Mesoporous Materials, vol. 86, no. 1-3, pp. 176-184, 2005.

[38] Z. Huo, X. Xu, Z. Lü et al., "Synthesis of zeolite NaP with controllable morphologies," Microporous and Mesoporous Materials, vol. 158, pp. 137-140, 2012.

[39] H. G. Karge, M. Hunger, and H. K. Beyer, "Characterization of zeolites-infrared and nuclear magnetic resonance spectroscopy and X-ray diffraction," in Catalysis and Zeolites, pp. 198-326, Springer, Berlin, Germany, 1999.

[40] P. Kartick, G. Sourav, and M. K. Naskar, "A facile synthesis of ZSM-11 zeolite particles using rice husk ash as silica source," Materials Letter, vol. 87, pp. 87-89, 2012.

[41] L. Zhang, S. Liu, S. Xie, and L. Xu, "Organic template-free synthesis of ZSM-5/ZSM-11 co-crystalline zeolite," Microporous, and Mesoporous Materials, vol. 147, no. 1, pp. 117-126, 2012.

[42] V. Sundraramurthy and N. Lingappan, "Isomorphic substitution of boron in ZSM-5 type zeolites using TBP as template," Journal of Molecular Catalysis, vol. 160, no. 2, pp. 367-375, 2000.

[43] M. A. Anang, D. Dodoo, B.-S. Ntiri, R. Zugle, and G. Ellen Fynn, "Improving the quality of locally produced vegetable oil in Ghana using zeolites ZSM-11," Chemical Science International, vol. 28, no. 4, pp. 1-13, 2019.

[44] M. M. J. Treacy and J. B. Higgins, Collection of Simulated XRD Powder Patterns for Zeolites, Elsevier, Amsterdam, Netherlands, 2001.

[45] M. M. J. Treacy and J. B. Higgins, "Collection of simulated XRD powder patterns for zeolite," in Commission of the International Zeolite Associations, Elsevier, Amsterdam, Netherlands, Fifth edition, 2007.

[46] M. Belhachemi and F. Addoun, "Comparative adsorption isotherms and modeling of methylene blue onto activated carbons," Applied Water Science, vol. 1, pp. 111-117, 2011.

[47] F. Rodriguez-Reinoso, "The role of carbon materials in heterogeneous catalysis," Carbon, vol. 36, pp. 159-175, 1998.

[48] I. K. Konstantinou and T. A. Albanis, "TiO ${ }_{2}$-assisted photocatalytic degradation of azo dyes in aqueous solution: kinetic and mechanistic investigations," Applied Catalysis B: Environmental, vol. 49, no. 1, pp. 1-14, 2004.

[49] X. Z. Li, W. Zhao, and J. C. Zhao, "Visible light-sensitized semiconductor photocatalytic degradation of 2, 4-dichlorophenol," Science in China Series B, vol. 45, pp. 421-425, 2002.

[50] P. Muthirulan, M. Meenakshisundararam, and N. Kannan, "Beneficial role of $\mathrm{ZnO}$ photocatalyst supported with porous activated carbon for the mineralization of alizarin cyanin green dye in aqueous solution," Journal of Advanced Research, vol. 4, pp. 479-484, 2013.

[51] D. R. Shinde, P. S. Tambade, M. G. Chaskar, and K. M. Gadave, "Photocatalytic degradation of dyes in water by analytical reagent grades $\mathrm{ZnO}, \mathrm{TiO}_{2}$, and $\mathrm{SnO}_{2}$ : a comparative study," Drinking Water Engineering and Science, vol. 10, no. 2, pp. 109-117, 2017. 